\title{
Article \\ Transient Phase-Driven Cyclic Deformation in Additively Manufactured 15-5 PH Steel
}

\author{
Tu-Ngoc Lam ${ }^{1,2}$, Yu-Hao Wu ${ }^{1}$, Chia-Jou Liu ${ }^{1}$, Hobyung Chae ${ }^{3}{ }^{\circledR}$, Soo-Yeol Lee ${ }^{3, *}$, Jayant Jain ${ }^{4, *}$, Ke An $^{5}(\mathbb{D}$ \\ and E-Wen Huang $1, *$ (D)
}

1 Department of Materials Science and Engineering, National Yang Ming Chiao Tung University, Hsinchu 30010, Taiwan; lamtungoc1310@gmail.com (T.-N.L.); paradise7139@gmail.com (Y.-H.W.); jasmine861025@gmail.com (C.-J.L.)

2 Department of Physics, College of Education, Can Tho University, Can Tho 900000, Vietnam

3 Department of Materials Science and Engineering, Chungnam National University, Daejeon 34134, Korea; highteen5@cnu.ac.kr

4 Department of Materials Science and Engineering, Indian Institute of Technology, New Delhi 110016, India

5 Chemical and Engineering Materials Division, The Spallation Neutron Source, Oak Ridge National Laboratory, Oak Ridge, TN 37831, USA; kean@ornl.gov

* Correspondence: sylee2012@cnu.ac.kr (S.-Y.L.); Jayant.Jain@mse.iitd.ac.in (J.J.); EwenHUANG@nctu.edu.tw (E.-W.H.)

check for updates

Citation: Lam, T.-N.; Wu, Y.-H.; Liu, C.-J.; Chae, H.; Lee, S.-Y.; Jain, J.; An, K.; Huang, E.-W. Transient

Phase-Driven Cyclic Deformation in Additively Manufactured 15-5 PH Steel. Materials 2022, 15, 777. https:// doi.org/10.3390/ma15030777

Academic Editor: Rubén Paz

Received: 23 December 2021

Accepted: 17 January 2022

Published: 20 January 2022

Publisher's Note: MDPI stays neutral with regard to jurisdictional claims in published maps and institutional affiliations.

Copyright: (c) 2022 by the authors. Licensee MDPI, Basel, Switzerland. This article is an open access article distributed under the terms and conditions of the Creative Commons Attribution (CC BY) license (https:/ / creativecommons.org/licenses/by/ $4.0 /)$.

\begin{abstract}
The present work extends the examination of selective laser melting (SLM)-fabricated 15-5 PH steel with the 8\%-transient-austenite-phase towards fully-reversed strain-controlled lowcycle fatigue (LCF) test. The cyclic-deformation response and microstructural evolution were investigated via in-situ neutron-diffraction measurements. The transient-austenite-phase rapidly transformed into the martensite phase in the initial cyclic-hardening stage, followed by an almost complete martensitic transformation in the cyclic-softening and steady stage. The compressive stress was much greater than the tensile stress at the same strain amplitude. The enhanced martensitic transformation associated with lower dislocation densities under compression predominantly governed such a striking tension-compression asymmetry in the SLM-built 15-5 PH.
\end{abstract}

Keywords: 15-5 PH stainless steel; in-situ neutron diffraction; selective laser melting; low-cycle fatigue; martensite transformation

\section{Introduction}

Selective laser melting (SLM), one of the most commonly used approaches in additive manufacturing (AM) technique, provides great abilities in fabricating layer by layer-built parts with complex geometry and customization, which significantly affects the anisotropy in mechanical properties with respect to the building directions [1-5]. The heterogeneous microstructure with the formation of defects in the SLM-manufactured alloys is inherently different from the homogeneous microstructure of the conventional cast and wrought alloys, causing unpredictable mechanical and fatigue properties of the SLM-fabricated components [2,6-8]. During the consecutive cycles of rapid heating and solidification under laser melting, the occurrence of defects, nucleation and growth, and phase transformation induces a metastable microstructure of the additive manufactured metals $[2,9,10]$.

The imperfections such as pores are strongly governed by the welding environments, which significantly decreased the mechanical properties of the steel welded joints [11]. Garcias et al. compared the material properties fabricated via conventional manufacturing and AM methods in which porosity and lack of fusion in the additive manufactured steels were found to have a negative effect on their mechanical and fatigue responses [12]. Post processing may reduce the imperfections and improve the properties of additive manufactured alloys [12]. Tailoring the intricate AM process with plenty fabrication conditions associated with various post treatments is full of challenges but a requisite for 
great optimization of mechanical and fatigue performances of the additive manufactured alloys.

The AM process parameters enable the controllable microstructure of precipitation hardened stainless steels consisting of austenite and martensite phases and thus strongly govern their mechanical properties [13-16]. The retained austenite produced in the additive manufactured steels during AM process enabled the transformation-induced plasticity [17]. Investigations on the influence of non-equilibrium retained austenite $\gamma$-phase and the strain-induced martensitic transformation under loading in the additive manufactured 15-5 PH and 17-4 PH steels have been extensively reported [4,14,18-25]. Huang et al. examined the tensile properties of the 15-5 PH steel with a tunable fraction of metastable transient-austenite-phase, which can be successfully tailored via the SLM process. They demonstrated that a higher fraction of transient austenite $\gamma$-phase was beneficial to the tensile properties of the SLM-built 15-5 PH steel [4]. Specifically, the SLM-built 15-5 PH with the $18 \%$-transient-austenite-phase revealed a more impressive strain hardening effect beyond yielding, while the specimen with the $8 \%$-transient-austenite-phase disclosed similar deformation behavior as the as-quenched martensite steel [4]. Chae et al. demonstrated the principal strengthening mechanisms via various heat treatments in tailoring the mechanical properties of the additive manufactured 15-5 PH steels [26].

In the other alloy systems, deformation-induced phase development was found, such as in the cobalt-based superalloys during monotonic and cyclic deformation [27]. Meanwhile, although comprehensive studies have been devoted to deciphering the straininduced phase transformation under monotonic tensile loading, the cyclic-induced phase transformation subjected to low-cycle-fatigue (LCF) deformation in the SLM-built 15-5 PH steel conducted by in-situ neutron diffraction is unclear and thus intriguing to examine.

We herein extend our earlier works $[4,24,28]$ towards the microstructural evolution of $\alpha$-matrix and transient $\gamma$-phase under cyclic continuous tension-compression loading. We explore the fully-reversed strain-controlled LCF deformation at a strain amplitude of $\pm 1.0 \%$ in the SLM-built 15-5 PH with the 8\%-transient-austenite-phase at room temperature. Insitu neutron-diffraction measurement was carried out to examine the cyclic-stress response during symmetric tension-compression cyclic loading by monitoring the microstructural evolutions [29], such as the dislocations [30], which are beneficial to elucidate the corresponding deformation mechanisms governing fatigue behavior of the SLM-built 15-5 $\mathrm{PH}$. The possible factors governing the applied stress response upon cyclic loading were reported.

\section{Materials and Methods}

The additive manufactured 15-5 PH steel was fabricated from the PH1 powder via SLM. The chemical composition was composed of $14.35 \mathrm{wt} \% \mathrm{Cr}, 4.03 \mathrm{wt} \% \mathrm{Ni}, 2.71 \mathrm{wt} \% \mathrm{Cu}$, $0.01 \mathrm{wt} \% \mathrm{Mn}, 0.99 \mathrm{wt} \% \mathrm{Si}, 0.5 \mathrm{wt} \% \mathrm{Mo}, 0.74 \mathrm{wt} \% \mathrm{Nb},<0.01 \mathrm{wt} \% \mathrm{C}$, and Fe balance. The laser power of $195 \mathrm{~W}$, spot size of $70 \mu \mathrm{m}$, and scanning rate of $1200 \mathrm{~mm} / \mathrm{s}$ were used. The vertically-built SLM 15-5 PH steel with the 8\%-transient-austenite-phase used in this study was produced such that the building direction was parallel to the loading direction, shown in the inset of Figure 1. More details of the 8\%-transient-austenite-phase specimen can be referred in our previous study [4].

In-situ neutron-diffraction measurements were carried out using the VULCAN engineering diffractometer at the Spallation Neutron Source (SNS) of the Oak Ridge National Laboratory (ORNL) [31-34]. The neutron-diffraction profiles were recorded simultaneously in both loading and transverse directions using two orthogonal detectors situated at $\pm 90^{\circ}$ from the incident neutron beam. The axial and transverse detectors collect the diffraction patterns from crystallographic orientations parallel and perpendicular to the applied loading direction, respectively. The LCF test was conducted with a maximum tensile strain of $1.0 \%$ and a maximum compressive strain $-1.0 \%$ at a cyclic frequency of 1 Hz. The cylindrical dog-bone-shaped specimen used for LCF loading had a total length of $70 \mathrm{~mm}$, a gauge length of $10 \mathrm{~mm}$, and a diameter of $6 \mathrm{~mm}$, shown in the inset of Figure 1 . 
Neutron-diffraction profiles were recorded during LCF test in a strain-controlled mode at maximum tensile and compressive strains of $1.0 \%$ and $-1.0 \%$ of each fatigue cycle until the specimen was fractured. The procedures for in-situ neutron-diffraction experiments and data analysis followed our earlier protocol [4]. The neutron-diffraction patterns were fitted using the general structure analysis system II (GSAS-II) [35] for phase characterization and profile analysis. Moreover, the development of dislocation density during LCF response for both $\alpha$-matrix and transient $\gamma$-phase was determined from the peak-width evolution following Tomota's method [36]. The evolution of phase fraction was obtained from the refined peak intensity as a function of fatigue cycles.

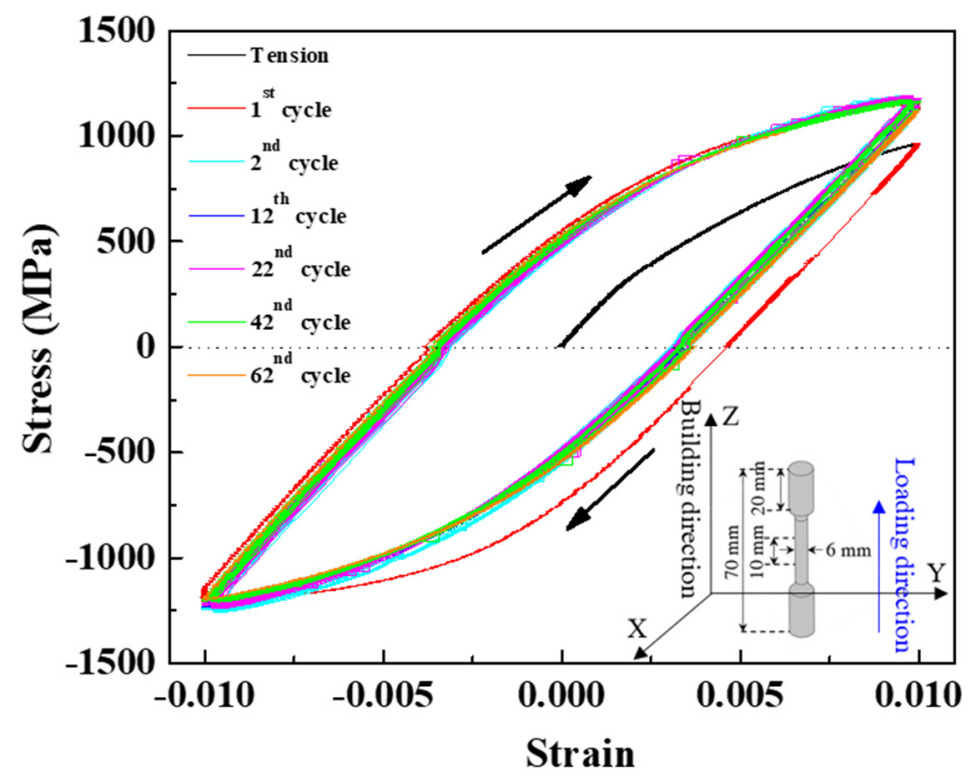

Figure 1. Stress-strain curves under LCF test in the SLM-built 15-5 PH steel. Schematic illustration of the vertically-built SLM 15-5 PH specimen is shown in the inset.

\section{Results}

\subsection{Cyclic Stress-Strain Curves}

Figure 1 presents the hysteresis loops at several selected fatigue cycles under LCF test at a strain amplitude of $\pm 1.0 \%$ in the SLM-built $15-5 \mathrm{PH}$ steel. The initial loading was in tension. In the 1 st cycle, the stress value was $955 \mathrm{MPa}$ at $1.0 \%$ strain. During unloading and compression, the plastic deformation started, and the stress value was $1158 \mathrm{MPa}$ at $-1.0 \%$ strain, respectively. In reloading to tension, the stress value increased to $1118 \mathrm{MPa}$ at $1.0 \%$ strain, originating from the significant strain hardening from the 1st to 2 nd cycles. In the 2nd cycle, during unloading to zero, plastic strain decreased but the stress value at $-1.0 \%$ strain was higher compared to the 1st cycle. The softening and saturation stages then occurred up to the 62nd cycle at which the specimen was fractured.

\subsection{Cyclic-Induced Martensitic Transformation}

Figure 2 depicts the evolution of in-situ neutron-diffraction patterns at $1.0 \%$ strain at the 1st and 62nd cycles in both axial loading and transverse directions. The diffraction profiles of body-centered cubic (BCC) $\alpha$-matrix and face-centered cubic (FCC) $\gamma$-phase austenite assigned for each ( $\mathrm{h} \mathrm{k}$ l) were illustrated as the blue and red arrows, respectively. The intensity of ( $\left.\begin{array}{lll}1 & 1 & 0\end{array}\right)$ peak of $\alpha$-matrix in the transverse direction (Figure $2 \mathrm{c}$ ) was greater by $30 \%$ than that in the axial loading direction in the 1st cycle (Figure 2a). Upon cycling, the intensity of $\alpha$-matrix peaks (ferrite and martensite) significantly increased while that of $\gamma$-phase peaks dramatically decreased and almost disappeared at the 62nd cycle in both axial loading (Figure $2 \mathrm{~b}$ ) and transverse directions (Figure 2d). The neutron results indicated the cyclic-induced martensitic transformation in the SLM-built 15-5 PH during continuous tension-compression loading. 

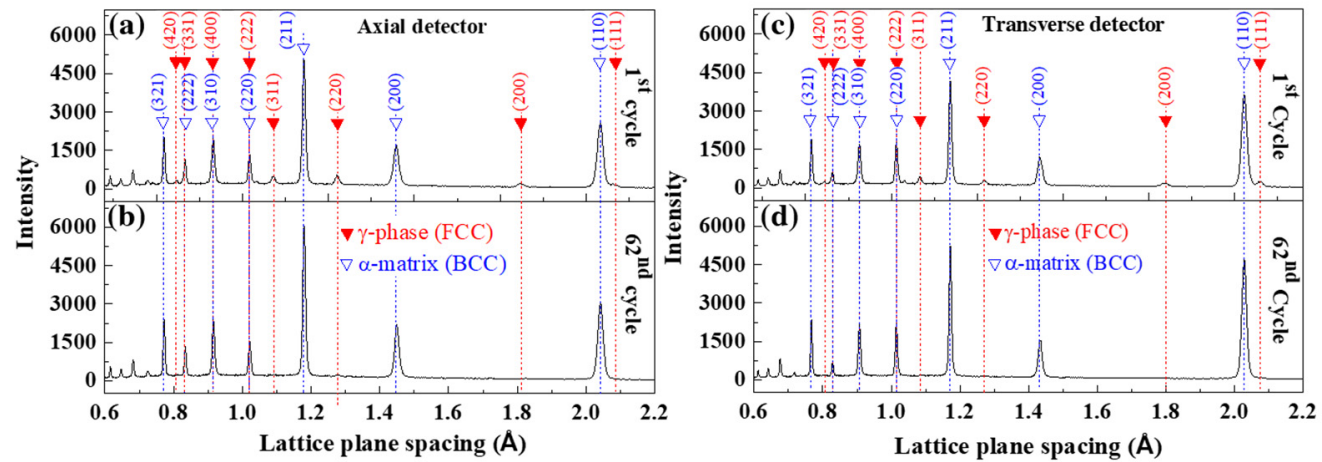

Figure 2. In-situ neutron-diffraction profiles at the maximum tensile strain of $1.0 \%$ in the axial loading direction at the (a) 1st cycle and (b) 62nd cycle. Those in the transverse direction at the (c) 1st cycle and (d) 62nd cycle in the SLM-built 15-5 PH steel.

\subsection{Tension-Compression Asymmetry Behavior}

Figure 3a describes the cyclic-stress amplitudes at the tensile strain of $1.0 \%$ (red circles $\bigcirc$ ) and compressive strain of $-1.0 \%$ (red squares $\square$ ) as a function of fatigue cycles from 1 to 62 under LCF response in the SLM-built 15-5 PH steel. Under tensile deformation, the specimen experienced an initial cyclic hardening in which the applied stress significantly increased from $955 \mathrm{MPa}$ at the 1st cycle to $1177 \mathrm{MPa}$ at the 22nd cycle, followed by a slightly cyclic-softening and steady behavior up to the 62nd cycle. Meanwhile, under compressive deformation, there was an increase of cyclic stress from $1158 \mathrm{MPa}$ to $1241 \mathrm{MPa}$ at the 2nd cycle where the cyclic-hardening/softening transition occurred, followed by a more obvious cyclic-softening and steady behavior until the 62nd cycle. Moreover, the compressive stress was much higher than the tensile stress at the same strain amplitude, suggesting an asymmetric response in tensile-compressive deformation in the SLM-built 15-5 PH steel. Such a remarkable tension-compression asymmetry behavior is one of the typical characteristics of the additive manufactured alloys [37,38].
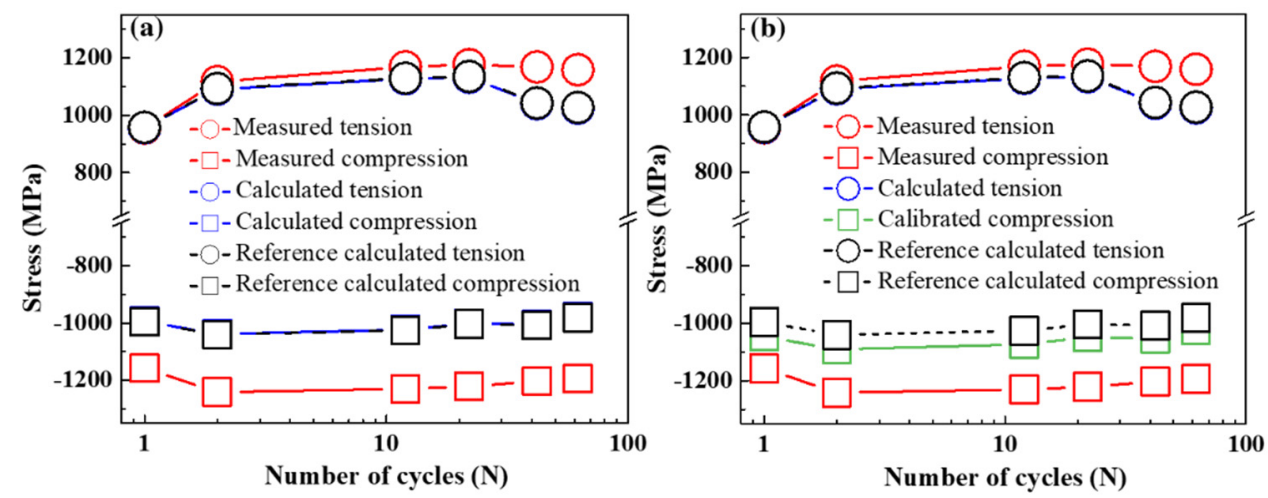

Figure 3. (a) The measured stress, calculated stress, and reference calculated stress at the maximum tensile and compressive deformations as a function of fatigue cycles. (b) The calculated compressive stress in (a) was replaced by the calibrated compressive stress.

Since the applied stresses vary differently under tension and compression at the same strain amplitude, clarifying the relationship between the macroscopic applied stress and microscopic lattice strain is necessary. We followed Wang et al.'s [39] and Young et al.'s [40] methods to estimate the effective phase stresses in understanding the role of $\alpha$-matrix and $\gamma$-phase under applied stresses. We calculated the average von Mises equivalent stress for each phase [41] on the assumption that two orthogonal transverse strain components 
$\left(\sigma_{11}=\sigma_{22}\right)$ are equal for cylindrical dog-bone sample. We applied the generalized Hooke's law shown as below.

$$
\begin{gathered}
\sigma_{11}^{\alpha}=\sigma_{22}^{\alpha}=\frac{E}{(1+v)(1-2 v)}\left\{(1-v) \varepsilon_{11}^{\alpha}+v\left(\varepsilon_{22}^{\alpha}+\varepsilon_{33}^{\alpha}\right)\right\}, \\
\sigma_{33}^{\alpha}=\frac{E}{(1+v)(1-2 v)}\left\{(1-v) \varepsilon_{33}^{\alpha}+v\left(\varepsilon_{22}^{\alpha}+\varepsilon_{11}^{\alpha}\right)\right\},
\end{gathered}
$$

where $E$ is Young's modulus, $v$ is Poisson's ratio, $\sigma_{33}$ and $\varepsilon_{33}$ are the stress and strain components along the axial loading direction, respectively, $\sigma_{11}$ and $\sigma_{22}$ are the stress components in the transverse direction, $\varepsilon_{11}$ and $\varepsilon_{22}$ are the strain components in the transverse direction, and $\alpha$ is the BCC $\alpha$-matrix. The same calculation is applied for the FCC $\gamma$-phase by substituting $\gamma$ for $\alpha$.

The calculated stress $\left(\sigma_{i j}^{\text {calculated }}\right)$ can be estimated as follows

$$
\sigma_{i j}^{\text {calculated }}=\sigma_{i j}^{\alpha}(1-f)+\sigma_{i j}^{\gamma} f,
$$

where $f$ is the volume fraction of the FCC $\gamma$-phase, $\sigma_{i j}^{\alpha}$ and $\sigma_{i j}^{\gamma}$ are the stress components of the BCC $\alpha$-matrix and FCC $\gamma$-phase, respectively.

Figure 3a presents the calculated tensile and compressive stresses obtained from the generalized Hooke's law shown in the blue circles $(\bigcirc)$ and squares $(\square)$, respectively, while the reference calculated tensile and compressive stresses using the reference Young's modulus [42] were depicted in the black circles $(\bigcirc)$ and squares $(\square)$, respectively. It can be seen from Figure $3 a$ that the calculated stresses were almost the same as the reference calculated stresses under both tensile and compressive deformations. Furthermore, the measured stress was much closer to the reference calculated stress under tension than under compression.

\subsection{Effect of Porous Structure on the Tension-Compression Asymmetry Behavior}

The outstanding tension-compression asymmetry behavior may be governed by various reasonable factors such as porous structure, phase transformation, and dislocation density. The pores, microvoids, or inclusions commonly exist in the additive manufactured steels due to thermal gradients or unmelted powder during the additive manufacturing process [37,43-45]. Thus, we first assumed that porous structure is one of the possible causes resulting in the tension-compression asymmetry behavior. To correlate the mechanical properties of porous materials with their relative densities, we recalled the Ashby and Gibson model (1997) as follows [46]:

$$
\begin{aligned}
& \sigma_{y}=\sigma_{y 0} \times \rho_{r e l}^{3 / 2}, \\
& E_{e f f}=E_{0} \times \rho_{r e l}^{2},
\end{aligned}
$$

where $\sigma_{Y}$ and $E_{e f f}$ are the yield strength and effective modulus of the porous material, respectively; $\sigma_{y 0}$ and $E_{0}$ are the yield strength and elastic modulus of the bulk material, respectively; and $\rho_{\text {rel }}$ is the relative density of the porous material.

We herein assumed that when the specimen experiences tensile deformation, the internal pores are stretched and the volume becomes larger. However, the internal pores are squeezed or even disappeared as the specimen undergoes compressive deformation. The deformation is presumably highly influenced by large internal porosity in tension. Therefore, the parameters of the porous material were expressed as the case of tension while the parameters of the bulk material were represented as the case of compression. Based on the measured Young's moduli obtained from the slopes of lattice strain versus engineering stress curves under tension and compression, the relative densities of $\alpha$-matrix and $\gamma$-phase calculated from Equation (5) were 0.970 and 0.794 , respectively. The stress components of $\alpha$ matrix and $\gamma$-phase of the porous material under compression were accordingly adjusted by 
Equation (4) instead of Equation (2). The calibrated compressive stress was then calculated by Equation (3), which was shown in the green squares ( $\square$ ) in Figure 3b. Compared with the calculated compressive stress, the calibrated compressive stress was closer to the measured compressive stress. Despite taking the porous structure into consideration, the calibrated compressive stress was still inconsistent with the measured compressive stress, suggesting other factors governing the tension-compression asymmetry behavior besides the porous structure.

\subsection{Effect of Microscopic Change on the Tension-Compression Asymmetry Behavior}

Since the two phases of $\alpha$-matrix and $\gamma$-phase co-existed and there was martensitic transformation in the SLM-built 15-5 PH steel during cyclic loading, exploring the contribution of each phase to the macroscopically measured stresses under both tension and compression is necessary. Figure $4 \mathrm{a}$,b present the microscopically individual stresses of $\alpha$-matrix and $\gamma$-phase as a function of fatigue cycles, respectively. The individual stress of $\alpha$-matrix disclosed an obvious symmetry under tension and compression; however, the individual stress of $\gamma$-phase revealed an evident tension-compression asymmetry behavior upon cycling. The macroscopic tension-compression asymmetry was probably originated from the major contribution of $\gamma$-phase instead of $\alpha$-matrix. It should be noted that the phase fraction should be taken into account when calculating the macroscopic stress of the specimen by Equation (3). Particularly, the phase fraction of $\gamma$-phase austenite (8 wt $\%)$ was much lower than that of $\alpha$-phase ferrite (92 wt \%) before the fatigue test. Moreover, the $\gamma$-phase austenite rapidly transformed to the martensite phase up to the 2nd cycle, followed by a nearly complete martensitic transformation upon further cycling, as seen in the phase fraction evolution of $\alpha$-matrix and $\gamma$-phase in Figure $4 c, d$, respectively. Since there is a very small fraction of $\gamma$-phase austenite upon cycling, its effect on the macroscopic stress should be trivial. Therefore, the tension-compression asymmetry of $\gamma$-phase had a negligible influence on the macroscopic tension-compression asymmetry behavior in the SLM-built 15-5 PH.
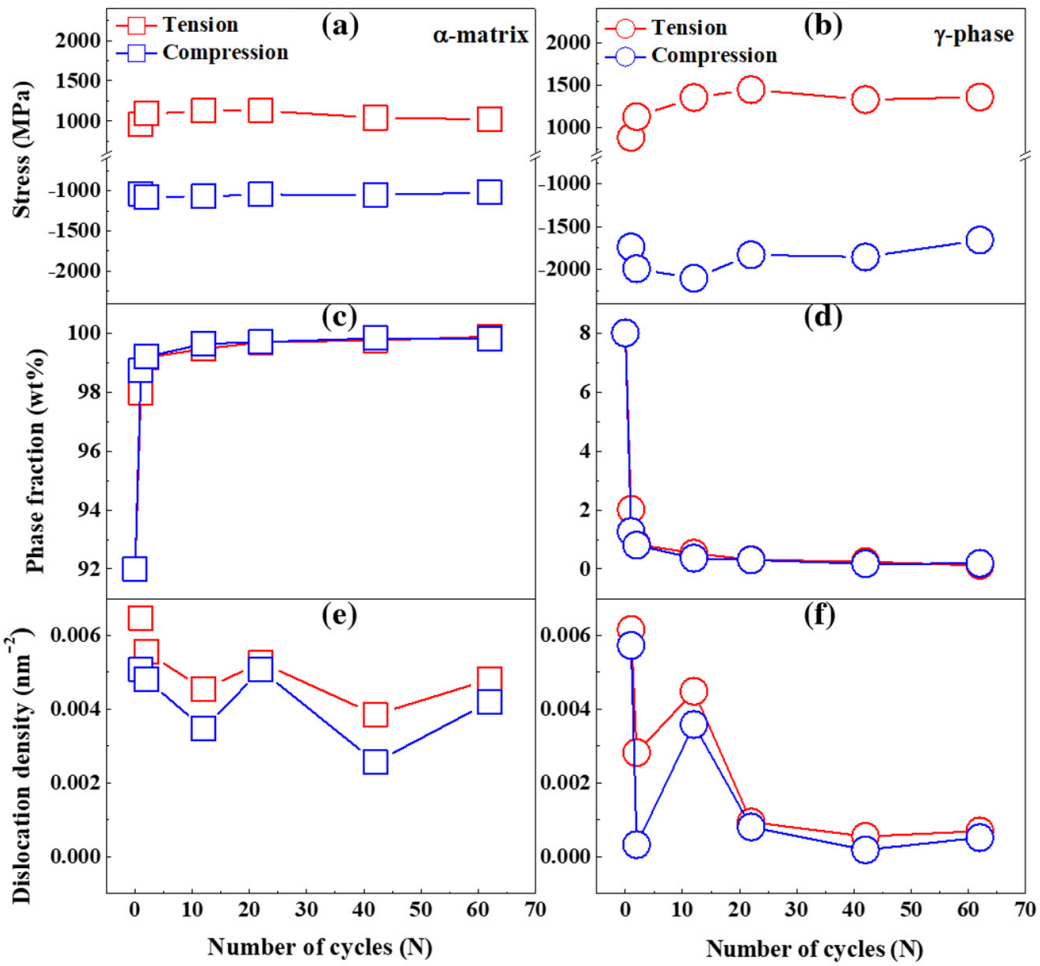

Figure 4. The microscopically individual stresses of the (a) $\alpha$-matrix and (b) $\gamma$-phase; the phase fraction of the (c) $\alpha$-matrix and (d) $\gamma$-phase; the dislocation density of the (e) $\alpha$-matrix and (f) $\gamma$-phase as a function of fatigue cycles. 
Accompanying with the martensitic transformation, examination of microstructural evolution of the individual phases during cyclic loading is indispensable to understand the tension-compression asymmetry in the SLM-built 15-5 PH steel. Figure 4e,f show the dynamic evolution of dislocation densities of $\alpha$-matrix and $\gamma$-phase as a function of fatigue cycles, respectively. The evolution of dislocations under tension and compression disclosed similar trends in both $\alpha$-matrix and $\gamma$-phase, however, the dislocations exhibited lower densities in compression than in tension for both $\alpha$-matrix and $\gamma$-phase, implying the different contribution of dislocation activities to the tension-compression asymmetry in the SLM-built 15-5 PH specimen.

\section{Discussion}

Since the pores are usually formed in the fabricated alloys during SLM process and they strongly affect their mechanical properties, we further calculated the porosity of the SLM-built 15-5 PH by the Equation (6) [47].

$$
P(\%)=\left(1-\frac{\rho_{\text {measured }}}{\rho_{\text {theoretical }}}\right) * 100,
$$

where $\rho_{\text {measured }}$ is the measured density of the SLM-built 15-5 PH specimen and $\rho_{\text {theoretical }}$ is the theoretical density of the material.

The measured density of the SLM-built 15-5 PH measured by the Archimedes method was $7.759 \mathrm{~g} / \mathrm{cm}^{3}$, which was similar to the density of the SLM-built 17-4PH steel with similar manufacturing parameters measured by Hengfeng $\mathrm{Gu}$ et al. [48]. The porosity of the SLM-built 15-5 PH specimen was determined to be $0.53 \%$, which is insufficient to have a major impact on the tension-compression asymmetry behavior [49]. The results inferred that the porosity had relatively minor contributions to the tension-compression asymmetry behavior in the SLM-built 15-5 PH specimen.

The phase fraction evolution of both $\alpha$-matrix and $\gamma$-phase was similar under tension and compression in Figure $4 \mathrm{c}, \mathrm{d}$, however, there was a noticeable difference in the amount of martensitic transformation between tension and compression. A slightly higher fraction of the cyclic-induced martensite phase was visible under compression than under tension in the cyclic-hardening region, while no evident discrepancy of martensitic transformation was seen in the cyclic-softening and steady stage. Since the martensite phase is harder than the other phases, the more pronounced fraction of cyclic-induced martensite phase under compression significantly contributes to the higher cyclic compressive stress at the same strain amplitude and thus the more hardening behavior under compression.

In Figure $4 \mathrm{e}, \mathrm{f}$, although the dislocation densities of both $\alpha$-matrix and $\gamma$-phase decreased with increasing fatigue cycles, the dislocation densities of $\gamma$-phase dramatically reduced upon cycling. Such a drastic degradation of dislocation density of $\gamma$-phase leads to the cyclic-softening region [50]. Furthermore, the dislocation densities of both $\alpha$-matrix and $\gamma$-phase were lower under compression rather than under tension. The decreased dislocation densities under the fatigue test were also observed under the monotonic tensile test in the SLM-built 15-5 PH, which was assigned to the coalescence of dislocations during martensitic transformation [4]. Lower dislocation densities under compression promote the nucleation and growth of the martensite phase [50], which is beneficial to the higher cyclic stress under compression.

\section{Conclusions}

We examined the cyclic-stress response under strain-controlled LCF test in the SLMbuilt 15-5 PH steel with 8\%-transient-austenite-phase and identified the possible underlying factors. The SLM-built 15-5 PH specimen was fractured at the 62nd cycle upon cycling loading at a strain amplitude of $\pm 1.0 \%$. The compressive stresses of $1158 \mathrm{MPa}$ and $1241 \mathrm{MPa}$ were higher than the tensile stresses of $955 \mathrm{MPa}$ and $1118 \mathrm{MPa}$ at the 1 st and 2nd cycles, respectively. The effect of inherent pores and porosity on the SLM-built 15-5 PH plays a secondary role in higher cyclic compressive stress. Such a hardening response under 
compression was mainly ascribed to the primary martensitic transformation coupled with lower dislocation densities. Understanding the principal microstructural changes governing the applied stress amplitude upon cycling is helpful for the design of fatigue-resistant additive manufactured alloys.

Author Contributions: Conceptualization, E.-W.H.; investigation, C.-J.L. and Y.-H.W.; resources, H.C., S.-Y.L., J.J. and K.A.; writing-original draft preparation, T.-N.L.; writing-review and editing, S.-Y.L. and E.-W.H.; supervision, E.-W.H.; project administration, E.-W.H. All authors have read and agreed to the published version of the manuscript.

Funding: Research conducted at ORNL's Spallation Neutron Source was sponsored by the Scientific User Facilities Division, Office of Basic Energy Sciences, US Department of Energy. The authors are grateful to the support of the Ministry of Science and Technology (MOST) Programs MOST 110-2224-E-007-001 and MOST 108-2221-E-009-131-MY4. This work was financially supported by the "Center for the Semiconductor Technology Research" from The Featured Areas Research Center Program within the framework of the Higher Education Sprout Project by the Ministry of Education (MOE) in Taiwan. Also supported in part by the Ministry of Science and Technology, Taiwan, under Grant MOST 110-2634-F-009-027. This work was supported by the Higher Education Sprout Project of the National Yang Ming Chiao Tung University and the MOE, Taiwan. SYL was supported by the National Research Foundation (NRF) grant funded by the Korean Government (2021R1A4A1031494, 2020K2A9A2A06070856).

Data Availability Statement: The data presented in this study are available on request from the corresponding author.

Acknowledgments: E.-W.H. and his group members very much appreciate the financial support from the National Synchrotron Radiation Research Center (NSRRC) Neutron Program.

Conflicts of Interest: The authors declare no conflict of interest.

\section{Nomenclature}

Selective laser melting

Low-cycle fatigue

Additive manufacturing

Spallation Neutron Source

Oak Ridge National Laboratory

General structure analysis system II

Body-centered cubic

Face-centered cubic

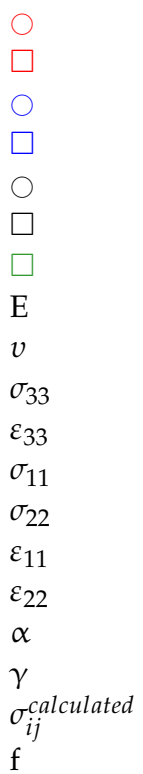

SLM

LCF

$\mathrm{AM}$

SNS

ORNL

GSAS-II

BCC

FCC

Measured tensile stress

Measured compressive stress

Calculated tensile stress

Calculated compressive stress

Reference calculated tensile stress

Reference calculated compressive stress

Calibrated compressive stress

Young's modulus

Poisson's ratio

Stress along the axial loading direction

Strain along the axial loading direction

Stress components in the transverse direction

Stress components in the transverse direction

Strain components in the transverse direction

Strain components in the transverse direction

BCC $\alpha$-matrix

FCC $\gamma$-phase

Calculated stress

Volume fraction of FCC $\gamma$-phase 


$\begin{array}{ll}\sigma_{i j}^{\alpha} & \text { Stress components of BCC } \alpha \text {-matrix } \\ \sigma_{i j}^{\gamma} & \text { Stress components of FCC } \gamma \text {-phase } \\ \sigma_{Y} & \text { Yield strength of porous material } \\ E_{e f f} & \text { Effective modulus of porous material } \\ \sigma_{y 0} & \text { Yield strength of bulk material } \\ E_{0} & \text { Elastic modulus of bulk material } \\ \rho_{\text {rel }} & \text { Relative density of porous material } \\ \mathrm{P}(\%) & \text { Porosity } \\ \rho_{\text {measured }} & \text { Measured density } \\ \rho_{\text {theoretical }} & \text { Theoretical density }\end{array}$

\section{References}

1. Thompson, S.M.; Bian, L.; Shamsaei, N.; Yadollahi, A. An overview of Direct Laser Deposition for additive manufacturing; Part I: Transport phenomena, modeling and diagnostics. Addit. Manuf. 2015, 8, 36-62. [CrossRef]

2. Shamsaei, N.; Yadollahi, A.; Bian, L.; Thompson, S.M. An overview of Direct Laser Deposition for additive manufacturing; Part II: Mechanical behavior, process parameter optimization and control. Addit. Manuf. 2015, 8, 12-35. [CrossRef]

3. Kok, Y.; Tan, X.P.; Wang, P.; Nai, M.L.S.; Loh, N.H.; Liu, E.; Tor, S.B. Anisotropy and heterogeneity of microstructure and mechanical properties in metal additive manufacturing: A critical review. Mater. Des. 2018, 139, 565-586. [CrossRef]

4. Huang, E.W.; Lee, S.Y.; Jain, J.; Tong, Y.; An, K.; Tsou, N.-T.; Lam, T.-N.; Yu, D.; Chae, H.; Chen, S.-W.; et al. Hardening steels by the generation of transient phase using additive manufacturing. Intermetallics 2019, 109, 60-67. [CrossRef]

5. Tseng, J.C.; Huang, W.C.; Chang, W.; Jeromin, A.; Keller, T.F.; Shen, J.; Chuang, A.C.; Wang, C.C.; Lin, B.H.; Amalia, L.; et al Deformations of Ti-6Al-4V additive-manufacturing-induced isotropic and anisotropic columnar structures: Insitu measurements and underlying mechanisms. Addit. Manuf. 2020, 35, 101322. [CrossRef] [PubMed]

6. Starr, T.; Rafi, H.; Stucker, B.; Scherzer, C.M. Controlling Phase Composition in Selective Laser Melted Stainless Steels; International Solid Freeform Fabrication Symposium: Austin, TX, USA, 2012; pp. 439-446.

7. Yadollahi, A.; Shamsaei, N.; Thompson, S.M.; Elwany, A.; Bian, L. Effects of building orientation and heat treatment on fatigue behavior of selective laser melted 17-4 PH stainless steel. Int. J. Fatigue 2017, 94, 218-235. [CrossRef]

8. Song, B.; Zhao, X.; Li, S.; Han, C.; Wei, Q.; Wen, S.; Liu, J.; Shi, Y. Differences in microstructure and properties between selective laser melting and traditional manufacturing for fabrication of metal parts: A review. Front. Mech. Eng. 2015, 10, 111-125. [CrossRef]

9. Herzog, D.; Seyda, V.; Wycisk, E.; Emmelmann, C. Additive manufacturing of metals. Acta Mater. 2016, 117, 371-392. [CrossRef]

10. Kim, J.S.; LaGrange, T.; Reed, B.W.; Taheri, M.L.; Armstrong, M.R.; King, W.E.; Browning, N.D.; Campbell, G.H. Imaging of Transient Structures Using Nanosecond in Situ TEM. Science 2008, 321, 1472-1475. [CrossRef] [PubMed]

11. Tomkow, J.; Janeczek, A.; Rogalski, G.; Wolski, A. Underwater Local Cavity Welding of S460N Steel. Material 2020, $13,5535$. [CrossRef]

12. Garcias, J.F.; Martins, R.F.; Branco, R.; Marciniak, Z.; Macek, W.; Pereira, C.; Santos, C. Quasistatic and fatigue behavior of an AISI H13 steel obtained by additive manufacturing and conventional method. Fatigue Fract. Eng. Mater. Struct. 2021, 44, 3384-3398. [CrossRef]

13. Hunt, J.; Derguti, F.; Todd, I. Selection of steels suitable for additive layer manufacturing. Ironmak. Steelmak. 2014, 41, 254-256. [CrossRef]

14. Facchini, L.; Vicente, N., Jr.; Lonardelli, I.; Magalini, E.; Robotti, P.; Molinari, A. Metastable Austenite in 17-4 PrecipitationHardening Stainless Steel Produced by Selective Laser Melting. Adv. Eng. Mater. 2010, 12, 184-188. [CrossRef]

15. Haghdadi, N.; Laleh, M.; Moyle, M.; Primig, S. Additive manufacturing of steels: A review of achievements and challenges. J. Mater. Sci. 2020, 56, 64-107. [CrossRef]

16. Lum, E.; Palazotto, A.N.; Dempsey, A. Analysis of the Effects of Additive Manufacturing on the Material Properties of 15-5PH Stainless Steel. In Proceedings of the 58th AIAA/ASCE/AHS/ASC Structures, Structural Dynamics, and Materials Conference, Grapevine, TX, USA, 9-13 January 2017. [CrossRef]

17. Lass, E.A.; Stoudt, M.R.; Williams, M.E. Additively Manufactured Nitrogen-Atomized 17-4 PH Stainless Steel with Mechanical Properties Comparable to Wrought. Metall. Mater. Trans. A 2019, 50, 1619-1624. [CrossRef]

18. LeBrun, T.; Nakamoto, T.; Horikawa, K.; Kobayashi, H. Effect of retained austenite on subsequent thermal processing and resultant mechanical properties of selective laser melted 17-4 PH stainless steel. Mater. Des. 2015, 81, 44-53. [CrossRef]

19. Mahmoudi, M.; Elwany, A.; Yadollahi, A.; Thompson, S.M.; Bian, L.; Shamsaei, N. Mechanical properties and microstructural characterization of selective laser melted 17-4 PH stainless steel. Rapid Prototyp. J. 2017, 23, 280-294. [CrossRef]

20. Rafi, H.K.; Starr, T.L.; Stucker, B.E. A comparison of the tensile, fatigue, and fracture behavior of Ti-6Al-4V and 15-5 PH stainless steel parts made by selective laser melting. Int. J. Adv. Manuf. Technol. 2013, 69, 1299-1309. [CrossRef]

21. AlMangour, B.; Yang, J.-M. Improving the surface quality and mechanical properties by shot-peening of 17-4 stainless steel fabricated by additive manufacturing. Mater. Des. 2016, 110, 914-924. [CrossRef]

22. Hsu, T.-H.; Chang, Y.-J.; Huang, C.-Y.; Yen, H.-W.; Chen, C.-P.; Jen, K.-K.; Yeh, A.-C. Microstructure and property of a selective laser melting process induced oxide dispersion strengthened 17-4 PH stainless steel. J. Alloys Compd. 2019, 803, 30-41. [CrossRef] 
23. Nong, X.D.; Zhou, X.L.; Wang, Y.D.; Yu, L.; Li, J.H. Effects of geometry, location, and direction on microstructure and mechanical properties of 15-5PH stainless steel fabricated by directed energy deposition. Mater. Sci. Eng. A 2021, 821, 141587. [CrossRef]

24. Chae, H.; Huang, E.W.; Jain, J.; Wang, H.; Woo, W.; Chen, S.-W.; Harjo, S.; Kawasaki, T.; Lee, S.Y. Plastic anisotropy and deformation-induced phase transformation of additive manufactured stainless steel. Mater. Sci. Eng. A 2019, $762,138065$. [CrossRef]

25. Carneiro, L.; Jalalahmadi, B.; Ashtekar, A.; Jiang, Y. Cyclic deformation and fatigue behavior of additively manufactured 17-4 PH stainless steel. Int. J. Fatigue 2019, 123, 22-30. [CrossRef]

26. Chae, H.; Luo, M.Y.; Huang, E.W.; Shin, E.; Do, C.; Hong, S.-K.; Woo, W.; Lee, S.Y. Unearthing principal strengthening factors tuning the additive manufactured 15-5 PH stainless steel. Mater. Charact. 2022, 184, 111645. [CrossRef]

27. Benson, M.L.; Liaw, P.K.; Saleh, T.A.; Choo, H.; Brown, D.W.; Daymond, M.R.; Huang, E.W.; Wang, X.L.; Stoica, A.D.; Buchanan, R.A.; et al. Deformation-induced phase development in a cobalt-based superalloy during monotonic and cyclic deformation Phys. B Condens. Matter 2006, 385-386, 523-525. [CrossRef]

28. Chae, H.; Huang, E.W.; Woo, W.; Kang, S.H.; Jain, J.; An, K.; Lee, S.Y. Unravelling thermal history during additive manufacturing of martensitic stainless steel. J. Alloys Compd. 2021, 857, 157555. [CrossRef] [PubMed]

29. Huang, E.W.; Chang, C.K.; Liaw, P.K.; Suei, T.R. Fatigue induced deformation and thermodynamics evolution in a nano particle strengthened nickel base superalloy. Fatigue Fract. Eng. Mater. Struct. 2016, 39, 675-685. [CrossRef]

30. Huang, E.W.; Barabash, R.I.; Ice, G.E.; Liu, W.; Liu, Y.-L.; Kai, J.-J.; Liaw, P.K. Cyclic-loading-induced accumulation of geometrically necessary dislocations near grain boundaries in an Ni-based superalloy. JOM 2009, 61, 53. [CrossRef]

31. An, K.; Chen, Y.; Stoica, A.D. VULCAN: A “hammer" for high-temperature materials research. MRS Bull. 2019, 44, 878-885 [CrossRef]

32. An, K.; Skorpenske, H.D.; Stoica, A.D.; Ma, D.; Wang, X.-L.; Cakmak, E. First In Situ Lattice Strains Measurements Under Load at VULCAN. Metall. Mater. Trans. A 2010, 42, 95-99. [CrossRef]

33. Huang, E.W.; Lee, S.Y.; Woo, W.; Lee, K.-W. Three-Orthogonal-Direction Stress Mapping around a Fatigue-Crack Tip Using Neutron Diffraction. Metall. Mater. Trans. A 2011, 43, 2785-2791. [CrossRef]

34. Lam, T.-N.; Wu, S.-C.; Chae, H.; Chen, S.-W.; Jain, J.; Lee, S.Y.; An, K.; Vogel, S.C.; Chiu, S.-M.; Yu, D.; et al. Phase Stress Partition in Gray Cast Iron Using In Situ Neutron Diffraction Measurements. Metall. Mater. Trans. A 2020, 51, 5029-5035. [CrossRef]

35. Toby, B.H.; Von Dreele, R.B. GSAS-II: The genesis of a modern open-source all purpose crystallography software package. J. Appl. Crystallogr. 2013, 46, 544-549. [CrossRef]

36. Morooka, S.; Tomota, Y.; Kamiyama, T. Heterogeneous Deformation Behavior Studied by in Situ Neutron Diffraction during Tensile Deformation for Ferrite, Martensite and Pearlite Steels. ISIJ Int. 2008, 48, 525-530. [CrossRef]

37. Cyr, E.; Lloyd, A.; Mohammadi, M. Tension-compression asymmetry of additively manufactured Maraging steel. J. Manuf. Processes 2018, 35, 289-294. [CrossRef]

38. Chen, W.; Voisin, T.; Zhang, Y.; Florien, J.B.; Spadaccini, C.M.; McDowell, D.L.; Zhu, T.; Wang, Y.M. Microscale residual stresses in additively manufactured stainless steel. Nat. Commun. 2019, 10, 4338. [CrossRef] [PubMed]

39. Wang, Y.; Tomota, Y.; Harjo, S.; Gong, W.; Ohmura, T. In-situ neutron diffraction during tension-compression cyclic deformation of a pearlite steel. Mater. Sci. Eng. A 2016, 676, 522-530. [CrossRef]

40. Young, M.L.; Almer, J.D.; Daymond, M.R.; Haeffner, D.R.; Dunand, D.C. Load partitioning between ferrite and cementite during elasto-plastic deformation of an ultrahigh-carbon steel. Acta Mater. 2007, 55, 1999-2011. [CrossRef]

41. Shen, C.J.L.H. 3D finite element analysis of particle-reinforced aluminum. Mater. Sci. Eng. A 2002, 338, 271-281. [CrossRef]

42. Dakhlaoui, R.; Baczmański, A.; Braham, C.; Wroński, S.; Wierzbanowski, K.; Oliver, E.C. Effect of residual stresses on individual phase mechanical properties of austeno-ferritic duplex stainless steel. Acta Mater. 2006, 54, 5027-5039. [CrossRef]

43. Jagle, E.A.; Sheng, Z.; Kurnsteiner, P.; Ocylok, S.; Weisheit, A.; Raabe, D. Comparison of Maraging Steel Micro- and Nanostructure Produced Conventionally and by Laser Additive Manufacturing. Material 2016, 10, 8. [CrossRef] [PubMed]

44. Asgari, H.; Mohammadi, M. Microstructure and mechanical properties of stainless steel CX manufactured by Direct Metal Laser Sintering. Mater. Sci. Eng. A 2018, 709, 82-89. [CrossRef]

45. Khairallah, S.A.; Anderson, A.T.; Rubenchik, A.; King, W.E. Laser powder-bed fusion additive manufacturing: Physics of complex melt flow and formation mechanisms of pores, spatter, and denudation zones. Acta Mater. 2016, 108, 36-45. [CrossRef]

46. Sallica-Leva, E.; Jardini, A.L.; Fogagnolo, J.B. Microstructure and mechanical behavior of porous Ti-6Al-4V parts obtained by selective laser melting. J. Mech. Behav. Biomed. Mater. 2013, 26, 98-108. [CrossRef]

47. de Terris, T.; Andreau, O.; Peyre, P.; Adamski, F.; Koutiri, I.; Gorny, C.; Dupuy, C. Optimization and comparison of porosity rate measurement methods of Selective Laser Melted metallic parts. Addit. Manuf. 2019, 28, 802-813. [CrossRef]

48. Gu, H.; Pal, D.; Rafi, K.; Starr, T.; Stucker, B. Influences of Energy Density on Porosity and Microstructure of Selective Laser Melted 17-4PH Stainless Steel. In Proceedings of the 24th Annual International Solid Freeform Fabrication Symposium, Austin, TX, USA, 12-14 August 2013.

49. Wits, W.W.; Carmignato, S.; Zanini, F.; Vaneker, T.H.J. Porosity testing methods for the quality assessment of selective laser melted parts. CIRP Ann. 2016, 65, 201-204. [CrossRef]

50. Xu, Y.; Zhang, S.H.; Cheng, M.; Song, H.W. In situ X-ray diffraction study of martensitic transformation in austenitic stainless steel during cyclic tensile loading and unloading. Scr. Mater. 2012, 67, 771-774. [CrossRef] 